\title{
AN INVESTIGATION INTO THE PREVALENCE AND CAUSES OF DRUG AND CHEMICAL POISONING IN PATIENTS
}

\author{
MOHAMMAD ISLAMI VAGHAR* \\ Department of Nursing and Midwifery, Faculty of Medicine, Islamic Azad University, Tehran Branch, Tehran, Iran. \\ Email: drislamivaghar@yahoo.com
}

Received: 20 March 2018, Revised and Accepted: 21 May 2018

\section{ABSTRACT}

Objective: Oral or intravenous use of drugs in amounts higher than therapeutic doses can cause poisoning or death. This condition which is called poisoning accounts for $15-20 \%$ of referrals to emergency units. Most death cases in adults are also reported to be attributed to this condition. The present study was carried out to investigate the prevalence and causes of poisoning in patients who had referred to the emergency department of Tabriz's Sina Hospital in 2012-2013.

Methods: In so doing, a cross-sectional analytic descriptive study was carried out to examine the prevalence and causes of poisoning among the patients who had referred to the poisoning ward of Sina Hospital affiliated with Tabriz University of Medical Sciences.

Result: The results of the present study showed that toxicity was prevalent among $44.16 \%$ of the patients who had referred to the emergency department, and it was significantly higher among the women compared to the men. Of the studied 988 patients, 567 had used only one drug and 16 two drugs at the same time, 14 patients had abused drug and chemical materials, $80.3 \%$ of them had no history of suicide, and $49.7 \%$ were reported with poisoning with home drugs. The results also indicated no significant relationship between the type of drug and intentional poisoning.

Conclusion: It could be concluded that marital and occupational status were significantly related to intentional poisoning.

Keywords: Chemical Poisoning, Drugs, Emergency ward.

(C) 2018 The Authors. Published by Innovare Academic Sciences Pvt Ltd. This is an open access article under the CC BY license (http://creativecommons. org/licenses/by/4. 0/) DOI: http://dx.doi.org/10.22159/ajpcr.2018.v11i7.26080

\section{INTRODUCTION}

Poisoning which is the oral or intravenous use of a drug in amounts higher than therapeutic doses can lead to poisoning or death [1]. $15-20 \%$ of referrals to emergency units is related to this condition [2]. It is also reported as the most common cause of death in adults. As children aging 2-3 years are curious to explore objects orally, they account for the most cases of poisoning (37.5\%) which can be attributed to improper storage of drugs, detergents, and chemicals in homes [3]. Factors such as unintentional and intentional usage, overdose of drugs, and sensitivity can also lead to poisoning [4]. Rural areas have been reported with more cases of poisoning due to any reason (intentional or unintentional) than urban areas. This difference between urban and rural areas is claimed to be related to their difference in terms of economic and industrial development, psychological problems, and lack of communication.

Different rates of poisoning prevalence are reported in different parts of Iran. Poisoning with sedatives, for instance, is common in Tehran, Mashhad, and Babol, and the most cases of poisoning in Guilan are caused by pesticides [5]. A large number of intentional and unintentional poisoning cases happen every year, which cause numerous problems ranging from mild illness and admission in Intensive Care Unit (ICU) wards to death. These problems also cause many economic, social, and health problems to societies, families, and individuals. Preventive measures are the best way to deal with these problems [6].

Intentional and unintentional poisoning is common as a result of the abundance and availability of drugs and toxic chemicals like pesticides and the abuse of opioids. As the relevant statistics indicate, approximately 30,000 cases of poisoning occur in Tehran every year as a result of drug and chemical poisoning. Of them, 12,000 patients are admitted in hospitals, 1200 in ICUs, and a minimum of 120 cases died in the end.

In developing countries, acute diseases are mainly caused by exposure to toxins. Sixty cases of death in Asia are reported to be caused by intentional poisoning. Overdose and unintentional or intentional poisoning are referred as a serious problem in emergency care centers in Turkey [6]. In recent years, there has been an increase in intentional poisoning in the UK, and it has become an important cause of emergency medical care [7].

Poisoning is the first common way of suicide in women and the second in men. In Sri Lanka as a developing country in Asia, poisoning is responsible for 100,000 hospitalizations and more than 1300 deaths per year [7]. The rate of suicide in developing countries is 15 times more than industrial countries [8]. Following accidents, suicide is the second most common cause of death among adolescents in Canada [9]. In their attempt to commit suicide, patients use different types of drugs and poisons, and it seems that there is a relationship between the type of drug used for suicide and the aim of patients and drug considerations. Since many medications such as benzodiazepines, tricycle antidepressants, and antihypertensive agents are found in most homes, and there is a relatively limited knowledge about the drugs, the present study was carried out to evaluate the prevalence and causes of poisoning in patients who had referred to the emergency department of Tabriz Sina Hospital in 2012-2013.

\section{METHODS}

The present investigation was a cross-sectional analytic descriptive study in which the patients who had referred to the poisoning ward of Tabriz Sina Hospital due to poisoning were examined with regard to the prevalence and causes of this condition. 
The study population included all patients with poisoning who had referred to the emergency ward of Sina Hospital of Tabriz University of Medical Sciences in 2012-2013, and the study sample consisted of the patients with poisoning who had referred to Sina Hospital.

The study sample included 988 patients with drug poisoning who were selected by a simple numbering method and were enrolled in the study. The inclusion criteria included patients who were older than 14-year-old, were poisoned with drugs and poisons, and were consent to contribute in the study. All of the qualified patients were selected for the study after they were provided with complete description of the topic.

Given the objectives of the study, descriptive analysis was used to analyze the data retrieved from the patients. The limitation of the study was the patients' psychological status, false answers given by the patients, and the patients' death, which led to failure to follow up the patients.

\section{Ethical considerations}

The study is performed according to the ethical principles of the Declaration of Helsinki. The study is approved by the ethical committee of Tehran Islamic Azad University of Medical Sciences. All patients were aware of the study conditions, and a written informed consent was obtained from each participant.

\section{RESULTS AND DISCUSSION}

The results of the study showed that the prevalence of toxicity in the patients who had referred to the emergency department was $44.16 \%$. Table 1 presents the patients' demographic information. It was observed that the prevalence of poisoning was significantly higher in women than men $(p=0.001)$.

The patients' age distribution is shown in Table 1 . As indicated, the age groups of 21-30 years and over 50 years account for most and least cases of poisoning, respectively. Table 1 also shows the patients' educational level.

It was concluded that there was a significant relationship between the patients' marital status and intentional poisoning $(\mathrm{p}=0.0001)$. Furthermore, there was a significant relationship between the patients' occupational status and intentional poisoning $(\mathrm{p}=0.003)$. Furthermore, there was a significant relationship between the lodging and intentional poisoning $(\mathrm{p}=0.016)$.

The results also showed that only $20.6 \%$ of the patients had other physical disorders. It was also observed that $5.8 \%, 31.8 \%$, and $3.7 \%$ of the patients did not negatively respond to questions related to family affairs, social affairs, and economic affairs, respectively. The psychological reasons for poisoning included anxiety (69.4\%) and panic disorder (5.4\%). No negative answers were given to the psychological aspect by $5.4 \%$ of the patients. There was a significant difference between physical reasons of poisoning, such that the minimum level was related to cancer and the maximum to neurologic disorders. Furthermore, there was a significant difference between personal reasons, such that the minimum level was related to the sense of invalidity and the maximum to disappointers.

Table 2 presents the frequency distribution of the types of drugs in the patients with poisoning who had referred to Sina Hospital, and frequency distribution of the types of drugs taken by the patients with poisoning who had referred to Sina Hospital is shown in Table 3. As seen, there was a significant difference between the mean levels of family levels, such that the minimum level was related to the sense of entente in spouses and the maximum level to drug usage.

There was also a significant difference in social causes, such that the minimum cases were related to the problems in workplace and the maximum to limited social activities. The results also indicated that the economic causes were significantly higher and social and psychological causes were significantly lower than the mean levels of physical, individual, and familial causes. Of 988 patients, $78.8 \%$ had intentionally committed suicide, and 14 patients had simultaneously undergone drug and chemical material poisoning.

Out of the 988 patients, 567 had only used one drug and 16 patients simultaneously two drugs. Fourteen patients had abused drugs and chemical materials. Of the studied patients, $93.7 \%$ had no history of psychological disorders and $80.3 \%$ had no history of suicide. The mean times of suicide attempt were $2.08 \pm 1.47$. It was concluded that $94.1 \%$ of the patients were poisoned orally and $49.7 \%$ were poisoned with home drugs. The results also showed that the type of drug and intentional poisoning was not significantly related $(\mathrm{p}=0.815)$, and there was no significant relationship between the treatment results and intentional poisoning $(\mathrm{p}=0.14)$. However, the patients' status after the treatment and the type of drug were significantly related $(p=0.023)$. Most of the patients $(97.2 \%)$ were discharged with recovery.

Due to the development of societies and the ease of access to drugs and poisons in recent years, there has been a sharp increase in the incidence of poisoning. Nowadays, one of the most important causes of hospital referrals is poisoning. According to the global statistics of poisoning,

Table 1: The demographic findings, the patients' age distribution, and educational level

\begin{tabular}{lllc}
\hline \multirow{2}{*}{ Variables } & \multicolumn{2}{c}{ Type of poisoning } & \multirow{2}{*}{ Total (\%) } \\
\cline { 2 - 3 } & \multicolumn{2}{c}{ Intentional (\%) Unintentional (\%) } & \\
\hline Gender & & & \\
$\quad$ Male & $549(55.56)$ & $94(9.51)$ & $643(65.1)$ \\
$\quad$ Female & $230(23.27)$ & $115(11.63)$ & $345(34.9)$ \\
Marital status & & & \\
$\quad$ Single & $291(29.45)$ & $93(9.41)$ & $386(39.06)$ \\
Married & $437(44.23)$ & $110(11.13)$ & $547(55.36)$ \\
$\quad$ Divorced & $51(5.16)$ & $6(0.6)$ & $57(5.76)$ \\
Employment & & & \\
$\quad$ Unemployed & $502(50.8)$ & $111(11.23)$ & $613(62.04)$ \\
$\quad$ Employed & $277(28.04)$ & $98(9.92)$ & $375(37.96)$ \\
Age group (years) & & \\
$\quad$ 14-20 & $182(18.42)$ & $34(3.44)$ & $216(21.86)$ \\
21-30 & $341(34.51)$ & $102(10.32)$ & $443(44.83)$ \\
$31-50$ & $229(23.18)$ & $53(5.36)$ & $282(28.54)$ \\
$>50$ & $27(2.83)$ & $20(2.02)$ & $47(4.75)$ \\
\hline
\end{tabular}

Table 2: Frequency distribution of types of drugs in patients with poisoning referred to Sina Hospital

\begin{tabular}{ll}
\hline Type of drug & Number (\%) \\
\hline Drug & $567(57.4)$ \\
Toxin or chemical & $407(41.2)$ \\
Drug or chemical poison & $14(1.4)$ \\
Sum & $988(100)$ \\
\hline
\end{tabular}

Table 3: Frequency distribution of types of drugs used by patients with poisoning referred to Sina Hospital

\begin{tabular}{ll}
\hline Drugs & Number (\%) \\
\hline Tricycles antidepressants & $87(14.6)$ \\
Anti-psychotic drugs & $20(3.4)$ \\
Steroidal anti-inflammatory & $54(9)$ \\
Barbiturates & $17(2.8)$ \\
Benzodiazepines & $182(30.5)$ \\
Opium & $146(24.5)$ \\
Cardiovascular drugs & $35(5.8)$ \\
Alcohol & $50(8.4)$ \\
Carbamate & $6(1)$ \\
Sum & $597(100)$ \\
\hline
\end{tabular}


this condition is classified as one of the most important causes of acute illnesses worldwide [10]. In the USA, poisoning causes an approximate annual number of 5 million patients to refer to hospitals [11]. Unfortunately, a large number of these patients are hospitalized as a result of intentional suicide toxicities [11]. The etiology of these patients includes drugs and poisons [12]. Easy access to these drugs makes these agents an available choice for individuals with suicide intention [13].

As a major problem in societies, suicide is responsible for $9 \%$ of all mortalities each year [14]. It is reported to be the $8^{\text {th }}$ major cause of mortality in the United States [15]. As forecasted, suicide will be listed in the 10 most important causes of death worldwide by 2020 [14]. The statistics related to suicide shows that since 1975, there has been an increase in suicide rate among men in England, Wales, Scotland, and Ireland; however, there has been a decrease in the mortality of women who intend to commit suicide [16].

The statistics related to suicide in Greece over the period of 19801990 shows that men committed suicide more than women at all ages; however, the cause and motivation of these cases were complicated [17]. In the present study, intentional poisoning was significantly more frequent in men than women.

Suicide at different age occurs due to different causes, for example, suicide in adolescent happens mainly as a result of social problems, relationship with parents, educational problems, social failures, dissimilarity in maturity, sense of loneliness which occurs at the time of personality statement, the parents' addiction, divorce, and abuse of drugs or alcohol [18-20]. The results of the present study showed that there was a significant relationship between marital status and intentional poisoning. It seems that special psychosocial status is an important cause that adolescents approach suicide. Several studies have focused on the incidence of suicide in this age range $[16,21]$.

Lower rate of suicide in Iran among elderly people can be due to strong familial relationships and the respectfulness of these age groups which is a tradition in Iran. In addition to the reasons mentioned above, the high rate of suicide with drugs can be the result of easy access to OTC drugs, incorrect administration of drugs, and overdose of some agents $[14,22]$.

The results of some studies like the one carried out by Carlston [14] in Sweden showed that most poisoning cases occurred as a result of antidepressant agents. The results of the present study indicated that benzodiazepines caused 182 cases of poisoning (32\%), opioids caused 146 cases (25.7\%), and tree cyclic antidepressants caused 87 cases $(15.3 \%)$. The high rate of poisoning with opioids can be attributed to abuse this drug for analgesia and the euphoria caused by these drugs [23]. The poisoning was reported as the most common cause of suicide among Greek women (18\%), while only $9.4 \%$ of suicide cases were reported to be associated with poisoning [17].

The results of a survey conducted in Iran showed that $93.4 \%$ of suicide cases among children occurred as a result of drug abuse and $3.3 \%$ by non-pharmacological methods (such as hanging), 30\% with tree cyclic antidepressants, and 20\% with anticonvulsants. According to the results of a study conducted in Sweden, more than $25 \%$ of suicide cases occurred among people over 65 years of age [4]. In the present study, however, $4.8 \%$ of poisoning cases occurred in people over 50 years. In Sweden, drug toxicity is a common method of suicide among young people who often use non-prescription drugs (usually acetaminophen) and elderly people consume prescribed drugs. Approximately, 33\% of poisoning cases were reported to be related with benzodiazepines and antidepressants [14]. Some studies have shown that benzodiazepine alone is responsible for the most cases of suicide [14,24,25].

In the present study, it was seen that benzodiazepines were the most common drugs used for suicide. In Poland, poisoning with tranquilizers and sedatives among adults has been reported to be $83.7 \%$ [26]. It is also reported that simultaneous use of psychiatric drugs and multiple drugs is a secondary concern [26]. Unfortunately, suicide rate among the youth is higher than other age groups $[27,28]$. In the present study, the highest percentage $(44.8 \%)$ of poisoning was observed in the age group of $21-30$ years and the lowest $(8.4 \%)$ in the age group above 50 years. The results of the studies conducted by Van-der-Hock [29], Kotwica [30], and GnyP and Lewandowska-stanek [31] indicate that the rate of suicide drugs and chemicals is higher among men than women.

In a study carried out in Denmark in 1992, it was revealed that the rate of acute intoxication with barbiturates, acetaminophen, and benzodiazepines was relatively higher in women than men [32]. In 1998, the results of a study conducted in New Zealand indicated that acetaminophen and antidepressants are used for suicide by a larger number of men than women [33-35]. It is also reported that gender and choosing the type of toxic agents are correlated, which is confirmed by Bill-Brahe's study carried out in Europe [34,36].

The results of the present study also showed that the type of agent used for suicide was correlated with the patients' gender, which can probably be attributed to gender requirements, for example, men are dealing with more chemical materials due to their gender and occupations.

\section{AUTHOR'S CONTRIBUTION}

Since there is only one author, author's contribution not need be mentioned.

\section{CONFLICTS OF INTEREST}

The author declares that there is no conflict of interest for this article.

\section{REFERENCES}

1. Olson KR. Poisoning and Drug Overdose. $6^{\text {th }}$ ed. New York: Mc Graw Hill; 2011.

2. Zarefazlohahi Z, Maleki M, Shaikhi N. Epidemiology of adult poisoning in Talegani hospital of Urmia 1383-1386. J Urmia Nur Midwifery Fac 2010;8:69-75

3. Dayan AD. Paine AJ. Mechanism of ehromium toxicity. Carcinogenicity and allergencity: Review of the literature from 1985 to 2004. Hum Exp Toxicol 2004;20:439-51.

4. Ghazinour M. Age and Gender differences in the use of various poisoning methods for deliberate parasuicide cases admitted to Loghman in Tehran. Suicide Life Threat Behav 2009;39:231-9.

5. Ahmadi H, Hosseini J, Rezaei M. Epidemiology of tramadol overdose in Imam Khomeini hospital, Kermanshah, Iran (2008). Behbood J 2011;15:72-77.

6. Masoumi G, Eizadi-Mood N, Akabri M, Sohrabi A, Khalili Y. Pattern of poisoning in Isfahan. J Isfahan Med Sch 2011;29:2003-10.

7. Kapur N, Turnbull P, Hawton K, Simkin S, Sutton L, Mackway-Jones K, et al. self poisoning suicides in England: A multicenter study. QJM 2005;98:589-978.

8. Eddleston M, Gunnell D, Karunaratne A, de Silva D, Sheriff MH, Buckley NA. Epidemiology of intentional self-poisoning in rural Sri Lanka. Br J Psychiatry 2005;187:583-4.

9. Shaw D, Fernandes JR, Rao C. Suicide in children and adolescents: A 10-year retrospective review. Am J For Med Pathol 2005;26:309-15.

10. Ellenhorn MJ, Barcelloux DG. Medical Roxicology; Prevention, Diagnosis and Treatment. $2^{\text {nd }}$ ed. New York: Elsevier; 1988. p. 4-5.

11. Fauci AS, Braunwuald E. Isselbacher KJ. Harrison s Principles of Internal Medicine. 14 ${ }^{\text {th }}$ ed. New York: Mcgraw-Hill Company; 1998. p. 2523-42.

12. Hawton K, Fayg J. Trends in deliberate self-harm in oxford, 1985-1995. Br J Psychiatry 1997; 171:55060.

13. Melev V, Mikhor D. Attempted suicide by poisoning in the Sofia region. Br J Psychiatry 1992;160:560-2.

14. Carlston A, Waern M, Allbeck P. Suicides by drug poisoning among the elderly in Sweden 1969-1996. Soc Psychiatr Epidemiol 1999;34:609-14.

15. Krulewitch CJ. The national strategy for suicide prevention. J Midwifery Women's Health 2001;46:304

16. Roesler J. The incidence of child suicide in Minnesota. Minn Med 1997;50:45-7. 
17. Zacharakis CA, Madianos MG, Papadimitriou GN, Stefanis CN. Suicide in Greece 1980-1995: Patterns and social factors. Soc Psychiatry Psychiatry Epidemiol 1998;33:471-6.

18. Sobhani AR, Shojaii-Tehrani H, Nikpour E, Noroozi-Rad N. Drug and chemical poisoning in Northern ran. Arch Iran Med 2000;3:32-6.

19. Lester D, Cantor CH, Leenaars AA. Suicide in the United Kingdom and Ireland. Eur Psychiatry 1997;12:300-4.

20. Suzuki O, Seno H, Watanabe-Suzuki K, Ishii A. Situations of poisoning and analytical toxicology in Japan. For Science Int 2000;113:331-8.

21. Groholt B, Wichstrom L. Suicide among children and adolescents in Norway. J Child Adolesc Psychiatry 1998;37:47381.

22. Townsend E, Hawton K, Harriss L, Bale E, Bond A. Substances used in deliberates self-poisoning 1985-1997: Trends and associations with age, gender, repetition and suicide intent. Soc Psychiatry Psychiatr Epidemiol 2001;36:228-34.

23. Joranson DE, Ryan KM, Gilson AM, Dahl JL. Trends in medical use and abuse of opioid analgesics. JAMA 2000;583:1710-4

24. Cattell H, Jolley DJ. One hundred cases of suicide in elderly people. $\mathrm{Br}$ J Psychiatry 1995;166:451-7.

25. Drummer OH, Ranson DL. Sudden death and benzodiazepines. Am J For Med Pathol 1996;17:33642.

26. Malgorzata K, Slawmir C, Wieslawa J, Anastazja J. The pattern of acute poisonings with drugs during the period 1991-1995. Toxicol Lett 1996;88:96

27. Abdollahi M, Jalali N. Aretrospective study of poisoning in Teharan.
J Toxicol Clin Toxicol 1997;33:387-93.

28. Gossel TA, Bricker JD. Poisoning due to analgesics during a period of 124 years in Denmark. Vgeskr Larg 1995;157:881-5.

29. Van-der-Hock W, Konradsen F, Athukora K. Pesticide poisoning: A major health care oroblem in Srilanka. Soc Sci Med 1998;46:495504.

30. Kotwica M, Czerczak S, Rogacsewska A. The pattern of poisoning with pesticides in Poland during the periods 1989-1990 and 1994-1995. Przegl Lek 1997;54:689-92.

31. Gny PK, Lewandowska-stanek H. The analysis of organophosphate poisoning cases treated at the center for acute poisonings in Lublin provinicial hospital in 1994-1996. Przegl-Lek 1997;54:734-6.

32. Nielsen AS, Nielsen B. Pattern of choice in preparation of attempted suicide by poisoning-with particular reference to changes in the pattern of prescriptions. Urgeskr Laeger 1992;154:1972-6.

33. Beautrais AL, Joyce PR, Mulder RT. Youth suicide attemps: A social and demographic profile. Aust NZJ Psychiatry 1998;32:349-57.

34. Bill-Brahe U, Kerkhof A, Deleo D. A repetition prediction study of European parasuicide population. Acta Psychiatr Scandin 1997;95:81-6.

35. Kassem M, Taweelh A. The role of honey with royal jelly in protecting the graafian follicles from the toxicity of the Adriamycin drug. Int J Pharm Pharm Sci 2015;7:376-85.

36. Sheela1 D, Geetha RV, Mohan SK, Vijayaraghavan R. A concept on the development of buprenorphine autoinjector for self and emergency administration. Int J Pharm Pharm Sci 2015;7:253-7. 